\title{
Posterior transdural discectomy: a new approach for the removal of a central thoracic disc herniation
}

\author{
Maarten H. Coppes • Nicolaas A. Bakker • \\ Jan D. M. Metzemaekers • Rob J. M. Groen
}

Received: 31 March 2011/Revised: 17 June 2011/ Accepted: 16 August 2011/Published online: 24 September 2011

(C) The Author(s) 2011. This article is published with open access at Springerlink.com

\begin{abstract}
Background The optimal surgical approach for thoracic disc herniation remains a matter of debate, especially for central disc herniation. In this paper, we present a new technique to remove central thoracic disc herniation, the posterior transdural approach, and report a series of 13 cases operated on in this way at our institute.

Methods Between September 2004 and October 2010, 13 patients with symptomatic central thoracic disc herniation were operated on, utilising this posterior transdural approach. All patients underwent magnetic resonance imaging (MRI) of the thoracic spine before surgery. All patients were followed at our outpatient department for at least 3 months. In addition, all patients were interviewed in April 2009 and February 2011 to evaluate the final results. A seven-point Likert scale was applied and the Frankel score was determined preoperatively and postoperatively. Additionally, a postoperative MRI was obtained for all but two patients.

Results The most frequently involved levels were T10-11 and T12-L1. Median operative time was 210 min (range 140-360). Three patients experienced reversible complications. No patient required spinal fixation. The median duration of hospitalisation was 6 days (range 4-20 days). With a median follow-up of 18 months, symptoms
\end{abstract}

M. H. Coppes and N. A. Bakker contributed equally to the preparation of this manuscript.

M. H. Coppes $(\bowtie)$ · N. A. Bakker · J. D. M. Metzemaekers ·

R. J. M. Groen

Department of Neurosurgery,

University Medical Center Groningen,

University of Groningen, P.O. Box 30.001,

9700 RB Groningen, The Netherlands

e-mail: m.h.coppes@nchir.umcg.nl improved in 12 patients (92\%), including the three patients with complications. One patient was unchanged (8\%), while none of the patients experienced worsening of symptoms. Conclusions The posterior transdural approach is well tolerated by the patient and has a relatively high success rate. It is a relatively simple and safe procedure, suitable for the operative treatment of almost all types of thoracic disc herniation, but especially the centrally located disc herniation.

Keywords Thoracic disc herniation .

Posterior approaches · Transdural

\section{Introduction}

Symptomatic thoracic disc herniation is uncommon and comprises only up to $5 \%$ of all disc herniations $[1,2]$. Till date, indications for surgery are controversial as little is known about the natural history of thoracic disc herniation $[2,3]$. Severe and progressive myelopathy is regarded as an absolute indication for surgery; however, the role of surgery in the control of radicular pain is uncertain. Moreover, the question of the optimal surgical approach for thoracic disc removal is a matter for debate, and it remains a challenge to find the most effective, safe, and relatively simple procedure, especially for the treatment of central thoracic disc herniation.

Several approaches have been advocated. Initially, laminectomy was the preferred approach, but outcomes were disappointing because of unsatisfactory operative results and high complication rates. Therefore, this technique has now been completely abandoned [4]. Newer approaches to the thoracic spine include the transpedicular approach $[5,6]$ and the transfacet pedicle-sparing approach 
$[7,8]$. These techniques seem to be relatively safe, especially when used to remove lateral thoracic disc herniations. For central thoracic disc herniations, however, these techniques are associated with high complication rates, as it is thought that the mechanical manipulation of the spinal cord required for the visibility produces direct mechanical injury to the cord, and also potentially interferes with spinal cord blood supply [9].

According to the recent literature, a costotransversectomy $[10,11]$, a lateral extracavitary (posterolateral approaches), or a classic transthoracic (anterolateral) approach may be more suitable for patients with central thoracic disc herniation [12], as these techniques allow for more direct access to the intervertebral disc and provide good visibility of the operative area of interest. The disadvantages of these techniques include their more extensive nature with, in the case of transthoracic approaches, potential pulmonary and mediastinal complications [12]. To avoid the complications of transthoracic surgery, minimally invasive thoracoscopic techniques have been developed in recent years [13, 14]. However, thoracoscopic surgery in general has a long learning curve, and familiarity with these approaches might not be easily achieved because of the small number of patients that present with symptomatic thoracic disc herniation.

In view of the aforementioned considerations, the ideal surgical procedure for medial thoracic disc herniations should be (i) effective in terms of postoperative results, (ii) safe in view of complication rates, (iii) suitable for all thoracic disc herniations (i.e. soft, calcified, lateral, or medial) with good view on the spinal cord and a good access to the disc, without the need to manipulate the neural structures, and (iv) easy and widely applicable.

In this paper, we present a novel technique for central thoracic disc herniation removal, the posterior transdural approach, and report on the early results of a series of 13 cases operated on in this way at our institute.

\section{Methods}

Technique of the posterior transdural approach

The posterior transdural technique reported here was developed and performed by the first author of this article (MHC). Patients were operated on in the prone position. After fluoroscopic confirmation of the appropriate level, a midline incision was made. After identification of the processus spinosus, a unilateral exposure was performed, directed to the side of most prominent prolaps of the disc herniation. Then a hemilaminectomy, a partial facetectomy, and a partial (medial) pediculectomy were performed (Fig. 1a). Then, under microscopic magnification, a posterolateral durotomy is performed, followed by the transsection of the denticulate ligament, which is tied up carefully with one stay suture. This manoeuvre lifts the spinal cord and slightly rotates it, thereby creating a corridor to the ventral aspect of the spinal canal (Fig. 1b). After this, the ventral dura is opened. Consequently, an excellent overview of the thoracic spinal cord is obtained (Fig. 1c, d). Both the spinal cord and the disc herniation are now under direct view, enabling discotomy/herniotomy with maximum visual control, and without touching the already compromised thoracic spinal cord. (Fig. 2). A "no-touch" strategy is the key to this approach. In case of a calcified disc herniation, a small diameter high speed drill is first used to reduce the disc mass. In addition, drilling into the disc and pushing calcified pieces of the disc downwards in the disc space creates a greater working space. After completion of thoracic spinal cord decompression (discotomy and removal of the disc herniation), the ventral dura defect is covered with a patch of either Tissuedura ${ }^{\circledR}$ or TachoSil ${ }^{\circledR}$, which is then extradurally sealed with fibrin glue. (Fig. 1e). Then the posterior durotomy is closed with running sutures and sealed with TachoSil ${ }^{\circledR}$ and/or fibrin glue. Dura closure is completed with the application of fibrin glue on the outer aspect of the ventral durotomy site. Wound closure is completed in the usual fashion in three layers, without the use of subfascial drainage. Postoperatively, the patient is restricted to flat bed rest for 3 days. Usually, hospital leave is on the sixth postoperative day.

\section{Presentation and analysis of operative cases}

Between September 2004 and October 2010, 13 patients with symptomatic central thoracic disc herniation were operated on, utilising the posterior transdural approach, at our center. Patient characteristics are listed in Table 1. The median age was 59 (range 20-79), male to female ratio 9:4. The median duration of symptoms before surgery was 60 weeks (range 5-300 weeks). Indications for surgery are also listed in Table 1 . Only patients with signs and symptoms of thoracic myelopathy (sensory deficits, motor deficits, hyperreflexia, and sphincter disturbances) due to central thoracic herniation-refractory to conservative treatment-were included. Isolated back pain as the only complaint was not an indication for surgery.

In all 13 patients, central thoracic disc herniation was diagnosed by means of an MRI. For all but two patients, a postoperative MRI was obtained. All patients were followed at our outpatient department for at least 3 months after initial surgery. In addition, all patients were interviewed in April 2009 and February 2011 to evaluate the postoperative results. A seven-point Likert scale was applied (Table 2) and the Frankel score (Table 3) was determined preoperatively and postoperatively for all patients. 
Fig. 1 a Schematic

representation after a vertical hemilaminectomy, partial facetectomy and a partial (medial) pediculectomy.

b Schematic representation after opening the dorsal dura mater and lifting up the denticulate ligament by sutures, thereby creating overview of the ventral dura. c, d Opening of the ventral dura in two steps. In c, the ventral dura is incised. In d, the ventral dura is lifted to the thoracic spine, thereby creating overview of the disc herniation. e Closure of the ventral dura. Tissuedura ${ }^{\circledR}$ is applied to the ventral defect
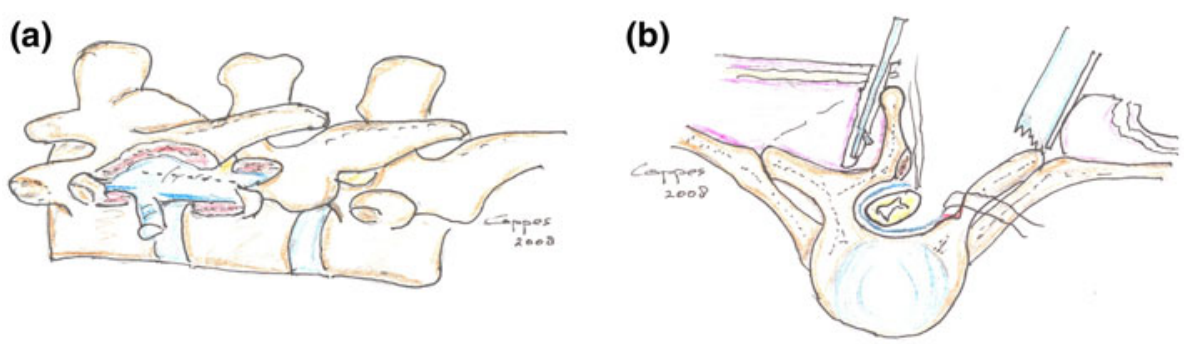

(c)

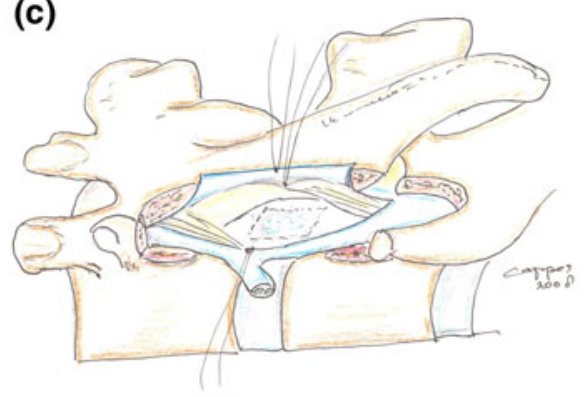

(d)

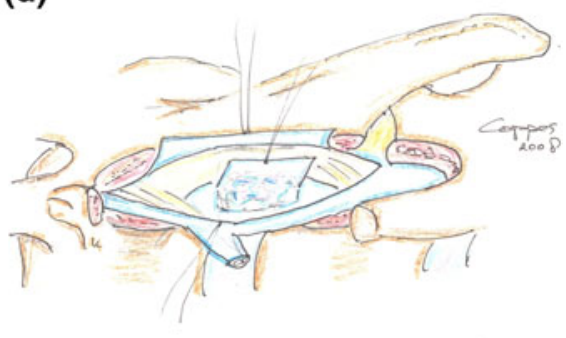

(e)

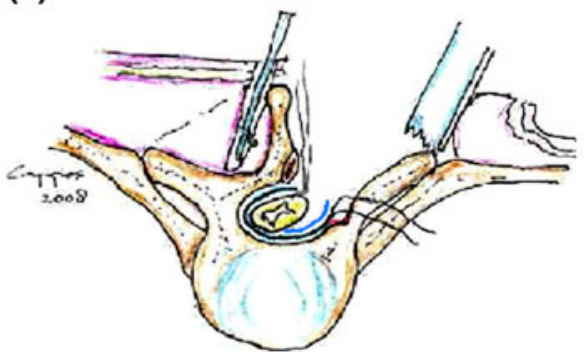

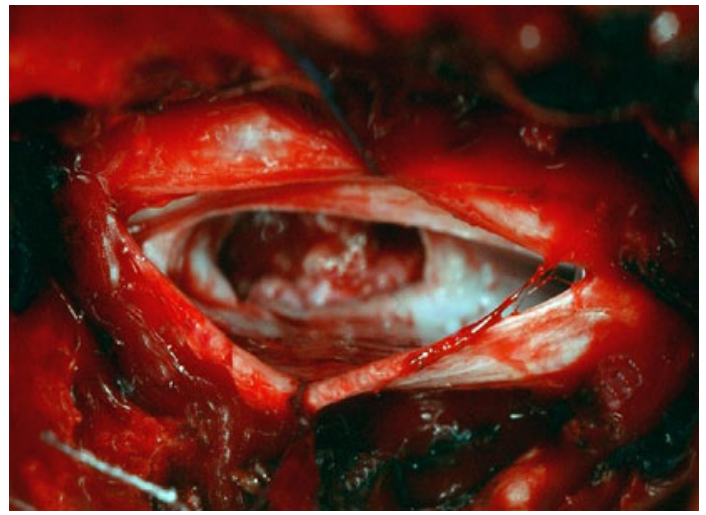

Fig. 2 View through the operation microscope with the dorsal and ventral dura opened, after removal of disc herniation and performing of discotomy. The thoracic spinal cord is tilted, by lifting the denticulate ligament with a stay suture

\section{Results}

Results are shown in Table 4. Most disc herniations were situated at T10-11 and T12-L1. The median operation time was 210 min (range 140-360 min). All thoracic disc herniations were extradural and four were calcified. Of note,
Table 1 Patient characteristics

\begin{tabular}{llllll}
\hline Patient & Age $^{\mathrm{a}}$ & Gender & $\begin{array}{l}\text { Myelopathic } \\
\text { symptoms }\end{array}$ & $\begin{array}{l}\text { Back } \\
\text { pain }\end{array}$ & $\begin{array}{l}\text { Duration of } \\
\text { symptoms }\end{array}$ \\
\hline 1 & 42 & F & Yes & No & 60 \\
2 & 64 & F & Yes & Yes & 275 \\
3 & 33 & M & Yes & No & 130 \\
4 & 67 & M & Yes & No & 156 \\
5 & 49 & M & Yes & Yes & 110 \\
6 & 65 & M & Yes & No & 178 \\
7 & 59 & F & Yes & No & 5 \\
8 & 77 & M & Yes & No & 10 \\
9 & 79 & F & Yes & No & 8 \\
10 & 42 & M & Yes & No & 10 \\
11 & 77 & M & Yes & No & 22 \\
12 & 46 & M & Yes & No & 300 \\
13 & 20 & M & Yes & No & 25 \\
\hline
\end{tabular}

${ }^{\mathrm{a}}$ Age (in years), ${ }^{\mathrm{b}}$ duration of symptoms (in weeks)

six patients suffered from giant disc herniations $(>40 \%$ of the diameter of the spinal canal, according to Hott et al. [15]. No patient required spinal fixation as in all patients only a unilateral partial facetectomy was performed and no 
Table 2 Likert scale

\begin{tabular}{ll}
\hline 1 & Complete resolution of complaints \\
2 & Near total resolution of complaints \\
3 & Some to moderate improvement \\
4 & No difference before and after surgery \\
5 & Some to moderate worsening of complaints \\
6 & Severe worsening of symptoms \\
7 & Symptoms worse than ever \\
\hline
\end{tabular}

Table 3 Frankel scale

\begin{tabular}{ll}
\hline A & Complete paralysis \\
B & Sensory function only below the injury level \\
C & Incomplete motor function below injury level \\
D & Fair to good motor function below injury level \\
E & Normal function \\
\hline
\end{tabular}

patient suffered from kyphotic deformities. The median time of hospital stay was 6 days (range 4-20 days). Three patients had postoperative complications; one patient experienced temporal hyperpathia after sacrificing one thoracic nerve root (Patient 2), one patient required reexploration because of CSF leakage (Patient 8), while the third suffered from a superficial wound infection without the need of a re-exploration (Patient 10). An example of pre- and postoperative MR imaging is shown in Fig. 3a and $\mathrm{b}$ (Patient 2).

Median follow-up was 18 months (range 4-66 months). At 3 months follow-up, myelopathic symptoms were partially or completely resolved in 12 patients (92\%), including the 3 patients who had postoperative complications (see also Table 4). In addition, complaints of back pain also diminished in both patients. None of the patients experienced worsening of myelopathic symptoms and/or back pain. In the patient whose symptoms did not resolve (case 7), postoperative MRI showed adequate decompression of the spinal cord. At the time of interview (in April 2009 and February 2011), all the patients who had experienced postoperative improvement were still satisfied with the postoperative results, as evaluated by the Likert scale (Tables 3, 4). The patient, whose symptoms did not resolve initially, experienced a very slight improvement in myelopathic complaints.

Preoperative and postoperative (at time of interview in April 2009 and February 2011) Frankel scores of 13 patients are also shown in Table 4. In six patients, the Frankel scores had improved. In the remaining seven patients, postoperative Frankel scores were unchanged (in two the Frankel score was already optimal [E] before surgery).

\section{Discussion}

The indication for operation and the optimal surgical approach for thoracic disc herniation have long been matters for debate. Owing to a general lack of knowledge of the natural course of thoracic disc herniation, there are no strict criteria for the operative treatment of thoracic disc herniation. In addition, a large number of surgical approaches to treat thoracic disc herniation have been presented over the past decades, obviously due to the lack of a uniform, effective, and safe approach. As a result,

Table 4 Surgery characteristics and outcome

\begin{tabular}{|c|c|c|c|c|c|c|c|c|c|c|}
\hline Patient & Level $^{\mathrm{a}}$ & Calcified $^{\mathrm{b}}$ & $\operatorname{Size}^{\mathrm{c}}$ & $\begin{array}{l}\text { Operative } \\
\text { time }^{d}\end{array}$ & $\begin{array}{l}\text { Hospital } \\
\text { stay }^{\mathrm{e}}\end{array}$ & Complications & Follow-up ${ }^{\mathrm{f}}$ & $\begin{array}{l}\text { Outcome } \\
\text { Likert scale }\end{array}$ & $\begin{array}{l}\text { Frankel } \\
\text { before }\end{array}$ & $\begin{array}{l}\text { Frankel } \\
\text { after }\end{array}$ \\
\hline 1 & T10-11 & Yes & 50 & 210 & 6 & No & 66 & 1 & $\mathrm{D}$ & $\mathrm{E}$ \\
\hline 2 & T6- $7^{\mathrm{g}}$ & Yes & 40 & 210 & 7 & Yes & 58 & 3 & $\mathrm{E}$ & $\mathrm{E}$ \\
\hline 3 & T12-L1 & No & 30 & 240 & 6 & No & 43 & 2 & $\mathrm{E}$ & $\mathrm{E}$ \\
\hline 4 & $\mathrm{~T} 7-8$ & No & 20 & 140 & 4 & No & 23 & 3 & $\mathrm{D}$ & $\mathrm{D}$ \\
\hline 5 & T8-9, T9-10 & No & 30 & 360 & 7 & No & 23 & 2 & $\mathrm{D}$ & $\mathrm{D}$ \\
\hline 6 & T12-L1 & No & 40 & 240 & 5 & No & 19 & 2 & $\mathrm{D}$ & $\mathrm{E}$ \\
\hline 7 & T10-11 & No & 50 & 240 & 4 & No & 18 & $3 / 4$ & $\mathrm{D}$ & $\mathrm{D}$ \\
\hline 8 & $\mathrm{~T} 10-11^{\mathrm{h}}$ & No & 30 & 180 & 15 & Yes & 17 & $2 / 3$ & $\mathrm{C}$ & $\mathrm{D}$ \\
\hline 9 & T11-12 & No & 30 & 180 & 7 & No & 15 & 2 & $\mathrm{C}$ & $\mathrm{C}$ \\
\hline 10 & T8-9 ${ }^{\mathrm{i}}$ & Yes & 50 & 240 & 20 & Yes & 12 & 1 & $\mathrm{C}$ & $\mathrm{E}$ \\
\hline 11 & T12-L1 & No & 50 & 150 & 6 & No & 10 & 2 & $\mathrm{C}$ & $\mathrm{D}$ \\
\hline 12 & T7-8 & No & 30 & 180 & 7 & No & 7 & 2 & D & $\mathrm{D}$ \\
\hline 13 & T11-12 & Yes & 35 & 210 & 6 & No & 4 & 2 & D & $\mathrm{E}$ \\
\hline
\end{tabular}

${ }^{a}$ Involved level(s), ${ }^{b}$ presence of a calcified disc herniation, ${ }^{c}$ maximum size of the herniated disc in percentage of the a/p diameter of the spinal canal, ${ }^{\mathrm{d}}$ duration of surgery (minutes), ${ }^{\mathrm{e}}$ postoperative hospital stay (days), ${ }^{\mathrm{f}}$ follow-up (months), ${ }^{\mathrm{g}}$ transient hyperpathia $\mathrm{T} 7 \mathrm{dermatome},{ }^{\mathrm{h}}$ persistent CSF leakage requiring re-exploration, isuperficial wound infection 

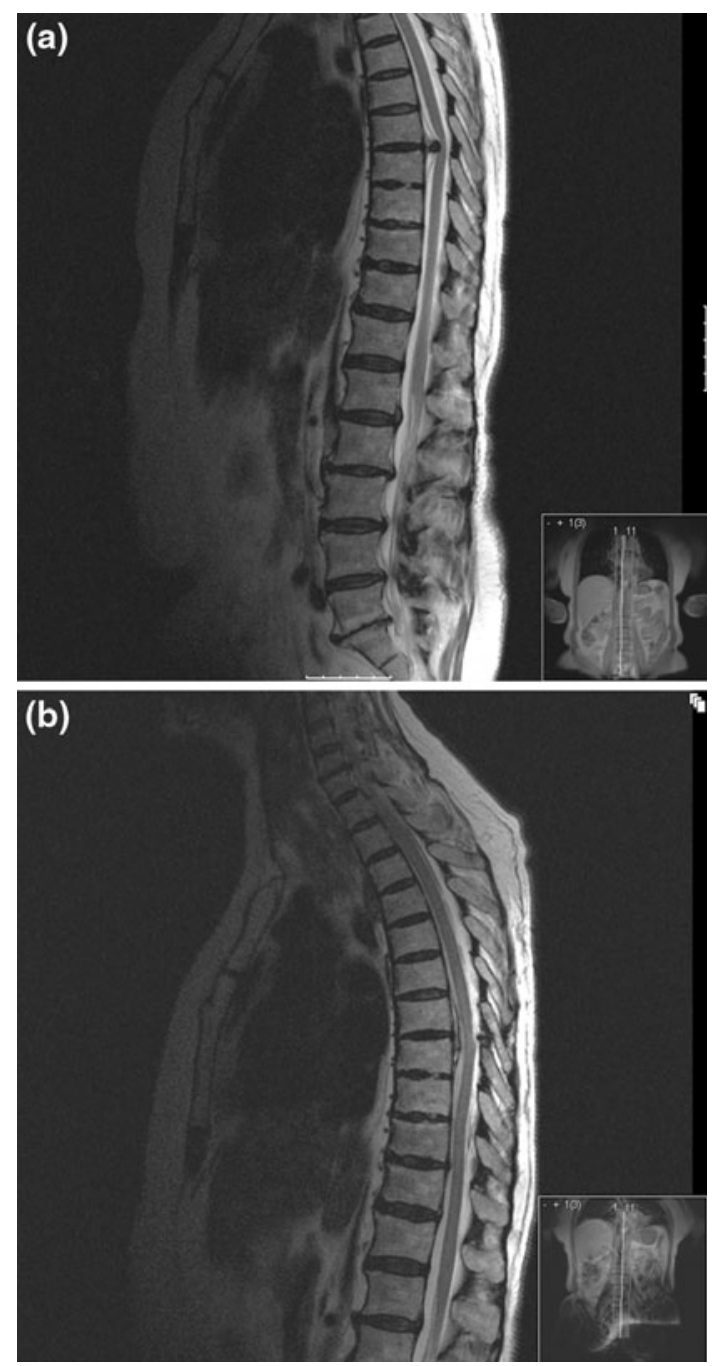

Fig. 3 a Pre-operative sagittal T2-weighted MR image of patient no. 2 showing a thoracic disc herniation at the level T6-T7. b Postoperative sagittal T2-weighted MR image of patient no. 2 showing the postoperative situation. The disc herniation cannot be visualised anymore

a very heterogeneous series of operative cases with thoracic disc herniation have been reported in the international medical literature. This frustrates proper interpretation and the comparison of the operative results of the series reported.

Except for the now abandoned laminectomy (which we will not discuss any further), the operative results with the various approaches for the removal of thoracic disc herniation seem comparable, with the majority $(60-80 \%)$ of patients showing relief in pain and/or an improvement of myelopathic signs and symptoms.

Levi et al. [6] showed that 26 out of 35 patients improved after being operated on using the unilateral transpedicular approach. The posterior transfacet pedicle sparing approach also showed fair to good results with improvement in approximately $80 \%$ of the patients [8].
However, in these series it remained unclear whether disc herniations were central or lateral. Both the unilateral transpedicular approach and the posterior transfacet pedicle sparing approach seem inappropriate for providing the exposure needed for safe and adequate removal of centrally located thoracic disc herniation.

For these reasons, transthoracic approaches have attracted interest in recent decades. It is thought that these approaches offer greater visibility of the thoracic disc, do not require any manipulation of the spinal cord and can be used for multilevel thoracic disc herniations [12]. Large calcified central thoracic disc herniations, which may require extensive manipulation to remove, are treated in this way in particular. The major disadvantage might be the invasiveness of the procedure. Hott et al. [15] described a series in which 20 patients suffered from giant disc herniations ( $>40 \%$ of the spinal canal) and advocated an open transthoracic approach instead of minimal invasive methods. Our results, however, in the six patients with giant disc herniations, are at least comparable to their numbers.

Thoracoscopic methods to treat thoracic disc herniation are being increasingly used $[14,16]$, especially because of the reduced morbidity rates compared with open thoracotomy. However, this method may require a relatively long learning curve. As numbers are small, not many spinal surgeons will be able to gain the experience to safely perform this approach [17].

In contrast to the material reported in the literature, our present series is relatively well documented, only reporting on centrally located thoracic disc herniation (some of them being giant) and with preoperative and postoperative MRI results. The symptomatic central thoracic disc herniation is probably the most challenging category of thoracic disc herniations because of the high risk of cord damage during operative removal. Even though the number of cases is small, the results of our preliminary series seem promising: 12 out of 13 (92\%) patients significantly improved clinically in terms of myelopathic complaints, while MR imaging revealed adequate decompression in all patients who received postoperative MRI, also in the patient who did not significantly improve after surgery.

From a surgical perspective, there are a number of advantages to the posterolateral transdural approach. The anatomical region is more familiar to spinal surgeons (orthopaedic or neurosurgeons), all types of thoracic disc herniation can be operated on (every thoracic segment and every type of disc herniation, including medial calcified disc herniation), and it is a relatively straightforward procedure with minimal blood loss and low perioperative morbidity. Moreover, no ICU admittance is required, no chest tube is needed (as is the case in transthoracic approaches), and no fixation of the thoracic spine is required. This is due to the unilateral approach, in which 
anticipation on postoperative thoracic spinal column instability is not necessary. In case of a preoperative deformed thoracic spinal column as part of the clinical problem, stabilization (or another approach) may be necessary. However, this is beyond the scope of our article as none of our patients suffered from a pre-operative kyphotic deformity. Of utmost importance, it appears that the outcome is at least equal to that obtained using other approaches.

Another advantage of the posterolateral transdural approach is the fact that this approach can, of course, also be used to remove lateral thoracic disc herniations. During surgery, it can be decided whether the dura should be opened or not. This should depend on the extent of the exposure needed to expose the disc herniation and the spinal cord adequately and safely. This offers the advantage that one single technique can be used to operatively approach almost all the different types of thoracic disc herniation.

There are, however, also patients to which in our opinion a transthoracic approach would probably more suitable, i.e. patients with very large ( $>50 \%$ of the diameter of the spinal canal) central, calcified disc herniations. In such cases, manipulation of the spinal cord would be unavoidable with a posterior approach, even with a bilateral approach.

In our series, complications occurred in three patients: (1) superficial wound infection, (2) transient neuropathic pain after sacrificing the $\mathrm{T} 7$ nerve root for exposure reasons, and (3) persistent postoperative CSF leakage, requiring re-exploration to close the dura defect. Although the latter is a serious complication, most spinal/neurosurgeons are familiar with such complications in other intradural procedures. Of note, only 1 out of 13 patients developed this complication. Moreover, none of the patients developed a symptomatic pseudomeningocele or intradural adhesions.

\section{Conclusion}

Although the present series is still small, the posterior transdural approach seems an appealing and promising procedure for the removal of a central thoracic disc herniation.

Conflict of interest None of the authors has any conflicts of interest to declare.

Open Access This article is distributed under the terms of the Creative Commons Attribution Noncommercial License which permits any noncommercial use, distribution, and reproduction in any medium, provided the original author(s) and source are credited.

\section{References}

1. Carson J, Gumpert J, Jefferson A (1971) Diagnosis and treatment of thoracic intervertebral disc protrusions. J Neurol Neurosurg Psychiatry 34:68-77

2. Stillerman CB (2000) Introduction to thoracic disc disease Neurosurg Focus 9:e1

3. Brown CW, Deffer PA Jr, Akmakjian J, Donaldson DH, Brugman JL (1992) The natural history of thoracic disc herniation. Spine 17:S97-S102

4. Arce CA, Dohrmann GJ (1985) Herniated thoracic disks. Neurol Clin 3:383-392

5. Le Roux PD, Haglund MM, Harris AB (1993) Thoracic disc disease: experience with the transpedicular approach in twenty consecutive patients. Neurosurgery 33:58-66

6. Levi N, Gjerris F, Dons K (1999) Thoracic disc herniation. Unilateral transpedicular approach in 35 consecutive patients. J Neurosurg Sci 43:37-42

7. Stillerman CB, Chen TC, Day JD, Couldwell WT, Weiss MH (1995) The transfacet pedicle-sparing approach for thoracic disc removal: cadaveric morphometric analysis and preliminary clinical experience. J Neurosurg 83:971-976

8. Stillerman CB, Chen TC, Couldwell WT, Zhang W, Weiss MH (1998) Experience in the surgical management of 82 symptomatic herniated thoracic discs and review of the literature. J Neurosurg 88:623-633

9. McCormick WE, Will SF, Benzel EC (2000) Surgery for thoracic disc disease. Complication avoidance: overview and management. Neurosurg Focus 9:e13

10. Simpson JM, Silveri CP, Simeone FA, Balderston RA, An HS (1993) Thoracic disc herniation. Re-evaluation of the posterior approach using a modified costotransversectomy. Spine 18:1872-1877

11. Kim KD, Babbitz JD, Mimbs J (2000) Imaging-guided costotransversectomy for thoracic disc herniation. Neurosurg Focus 9:e7

12. Vollmer DG, Simmons NE (2000) Transthoracic approaches to thoracic disc herniations. Neurosurg Focus 9:e8

13. Rosenthal D, Rosenthal R, de Simone A (1994) Removal of a protruded thoracic disc using microsurgical endoscopy. A new technique. Spine 19:1087-1091

14. Oskouian RJ, Johnson JP (2005) Endoscopic thoracic microdiscectomy. J Neurosurg Spine 3:459-464

15. Hott JS, Feiz-Erfan I, Kenny K, Dickman CA (2005) Surgical management of giant herniated thoracic discs: analysis of 20 cases. J Neurosurg Spine 3:191-197

16. Anand N, Regan JJ (2002) Video-assisted thoracoscopic surgery for thoracic disc disease: Classification and outcome study of 100 consecutive cases with a 2-year minimum follow-up period. Spine 27:871-879

17. Bartels RH, Peul WC (2007) Mini-thoracotomy or thoracoscopic treatment for medially located thoracic herniated disc? Spine 32:E581-E584 